
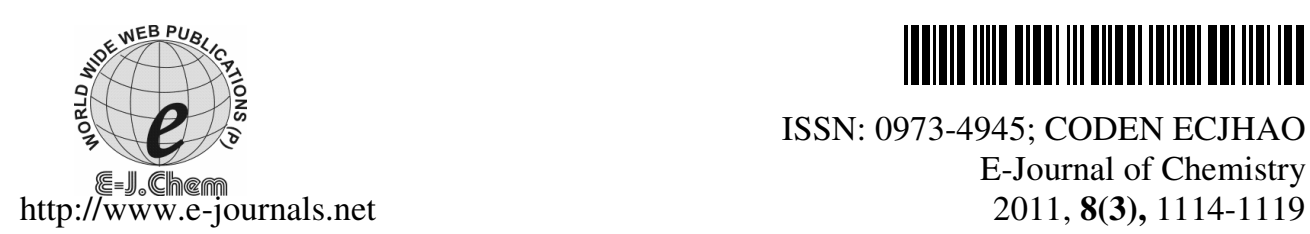

ISSN: 0973-4945; CODEN ECJHAO

E-Journal of Chemistry

2011, 8(3), 1114-1119

\title{
Supercritical Fluid Extraction of Metals Using Bis(2,4,4-trimethyl-pentyl)monothiophosphinic Acid as Chelating Agent for Subsequent ICP-MS Analyses of Mercury, Cadmium and Lead in Sediment
}

\author{
E. C. ROA $^{* \S}$, M. SCHULTZ ${ }^{\#}$ and M.B.CAPANGPANGAN ${ }^{\S}$ \\ ${ }^{\S}$ Department of Chemistry \\ College of Science and Mathematics, Mindanao State University-Iligan \\ Institute of Technology (MSU-IIT), 9200 Iligan City, Philippines \\ "Institute of Fisheries Research and Development \\ Mindanao State University-Naawan, 9023 Naawan, Misamis Oriental, Philippines \\ ${ }^{\#}$ School of Physical and Chemical Sciences \\ Queensland University of Technology, Brisbane, \\ Queensland 4001, Australia \\ bebottcroa@yahoo.co.uk
}

Received 19 November 2010; Accepted 21 January 2011

\begin{abstract}
This study investigated and validated the optimum conditions for a supercritical fluid extraction (SFE) method using bis(2,4,4-trimethylpentyl)monothiophosphinic acid as a chelating ligand, for subsequent ICP-MS analyses of mercury, cadmium and lead in sediment. Several combinations of pressure, temperature and modifier (P-T-M) conditions for SFE were tested and an appropriate collection solvent was also determined using a sediment certified reference material (CRM) as sample, to determine the optimum set of conditions. Validation results of the optimized method indicated high percent recoveries which are better compared to standard methods.
\end{abstract}

Keywords: SFE conditions, CRM, Cyanex, Optimization, Digestion

\section{Introduction}

Heavy metals such as mercury, cadmium and lead must be routinely monitored especially when possible sources are present, since, practically speaking, they are indestructible and totally non-degradable and thus, they accumulate in the environment ${ }^{1}$. These metals can be found in many different matrices and a plethora of experimental conditions has been used to determine their concentrations. 
Sample preparation is essential before the analysis of the total metal content is carried out. The total metal content cannot be correctly determined unless the sample is homogenized (to ensure that the suspended solids are evenly distributed) before it is digested. However, conventional metal extraction and digestion procedures are generally time-consuming, labor intensive and are expensive due to rising solvent costs.

The supercritical fluid extraction (SFE) method is becoming popular alternative technique $^{2}$ for the extraction of a wide range organometallic ${ }^{3}$ and inorganic analytes ${ }^{4,5}$. Successful SFE of metal compounds using chelating agents to improve the solubility of the metal in the supercritical fluid has been carried out from aqueous solutions and from solid matrices (filter paper, cellulose, sand and fly ash) impregnated with heavy metals ${ }^{6,7}$. This method avoids the use of toxic solvents and can be considered environmentally benign.

The aims of this study were: (1) to optimize a supercritical fluid extraction method for metals using bis(2,4,4-trimethylpentyl)monothiophosphinic acid as chelating agent for subsequent ICP-MS determination of $\mathrm{Hg}, \mathrm{Cd}$ and $\mathrm{Pb}$ in sediment; the expected concentrations were very low, so the use of ICP-MS was critical for accurate determination; and (2) to validate the method based on recovery studies using a certified reference material (CRM) for sediments as the sample.

\section{Experimental}

The certified reference material (CRM) for sediments used in this study contains certified values of $\mathrm{Hg}, \mathrm{Cd}$ and $\mathrm{Pb}$ together with 57 other elements. It is a lake deposit in powdered form with size less than $0.074 \mathrm{~mm}$, coded as NCSDC 73372 .

\section{Reagents}

The sample solutions were prepared using deionized water (specific resistance $>18 \mathrm{M} \Omega-\mathrm{cm}$, Academic Milli-Q Ultra-Pure Water System, Australia) and all working standard solutions were prepared by immediate serial dilution with $2 \%$ nitric acid solution. The reagents used such as nitric acid, methanol and chloroform were all analytical grade and of ultra-pure quality. The standard calibration solutions for ICP-MS analysis were prepared from a multielement ICP-MS standard (Sigma-Aldrich, Australia).

\section{Chelating agent}

The chelating agent used in this study, bis(2,4,4-trimethylpentyl)monothiophosphinic acid, has a density of $0.93 \mathrm{~g} / \mathrm{cm}^{3}$ and is also referred to as diisooctylthiophosphinic acid or cyanex 302, hereafter referred to as cyanex. Its structure is shown in Figure 1. The isooctyl groups are soluble in supercritical (SC) $\mathrm{CO}_{2}$ and metals bind to the sulfur and oxygen donor atoms to form a four membered metal chelate ring complex which is extractable by SFE.

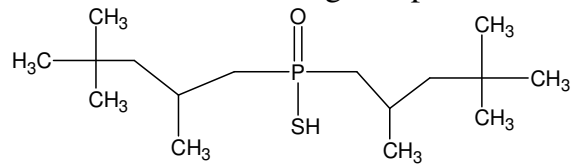

Figure 1. Structure of bis(2,4,4-trimethylpentyl)monothiophosphinic acid or cyanex Supercritical fluid extraction system

The supercritical fluid extraction of sediment CRM using bis(2,4,4-trimethylpentyl)monothiophosphinic acid as chelating agent was done using ISCO SFX 2-10 system (ISCO, Lincoln, NE), with $\mathrm{SC} \mathrm{CO}_{2}$ as the extraction solvent. The system is equipped with two ISCO 260D syringe pumps. 


\section{ICP-MS analysis of metals}

The elemental analyses were conducted using an Agilent 7500ce inductively coupled plasma mass spectrometer (ICP-MS) (Agilent Technologies, USA). This instrument is extremely sensitive, with a very large dynamic range that can measure analytes from the very low $\mu \mathrm{g} / \mathrm{L}(\mathrm{ppt})$ level to the upper $\mathrm{mg} / \mathrm{L}$ range (ppm) in one run, corresponding to a total range of 8 to 9 orders of magnitude.

The operating conditions of the ICP-MS instrument were optimized before the analysis was performed. Then, appropriate calibration standards were then measured. In this study an eight-point calibration corresponding to $0.05,5.0,25.0,50.0,100.0250 .0,500.0$ and $2000.0 \mu \mathrm{g} / \mathrm{L}$ was carried out for $\mathrm{Hg}, \mathrm{Cd}$ and $\mathrm{Pb}$ to generate a calibration curve with correlation coefficient of 0.9999 or better for each metal. The concentrations of the sample solutions were then determined from the calibration curve. In order to ensure that the instrument maintained its sensitivity, calibration standards were also analyzed at regular intervals during analytical runs.

\section{Optimization of conditions for the supercritical fluid extraction (SFE) method}

Seven different sets of SFE conditions for pressure, temperature and modifier (P-T-M) and two different collection solvents (Table 1) were tested using CRM (NCSDC 73372) as the sample, to determine the optimum set of conditions for SFE of sediment using cyanex as chelating agent. The SFE process was performed as follows: $0.5 \mathrm{~g}$ sample of CRM was placed in the sample cartridge, an exact volume $(500 \mu \mathrm{L})$ of the ligand was added and the mixture was mixed for 2 minutes. Then $0.5 \mathrm{~mL}$ of analytical grade methanol was added. Prior to placing the sample in the sample cartridge, a glass filter paper (Whatman, GF/B) was placed at both ends of the cell to avoid metal frit clogging ${ }^{9}$. The extraction fluid in all experiments was food grade carbon dioxide (BOC Gases, Australia). The chelation and extraction processes were performed for the static and dynamic time periods and at the temperatures shown in Table 1. The extracted metal chelates were delivered through capillary tubing made of polyetheretherketone (PEEK) $(0.254 \mathrm{~mm}$ inside diameter and $265 \mathrm{~mm}$ in length) and collected in $4 \mathrm{~mL}$ collection solvent, which was also varied from run to run, to determine the most appropriate solvent. The collected extracts were transferred to $25 \mathrm{~mL}$ test tubes. The walls of the collection tubes were washed with the collection solvent and the washing was added to the extract to make a final volume of approximately $10 \mathrm{~mL}$. The resulting solution in the test tube was covered with cotton and allowed to evaporate inside a fume hood. The residue was treated with $1 \mathrm{~mL}$ hot concentrated nitric acid ${ }^{10}$, transferred into a $10 \mathrm{~mL}$ volumetric flask, diluted to the mark with deionized water and analyzed by ICP-MS.

Table 1. Pressure-temperature-modifier (P-T-M) conditions applied during the SFE of CRM (NCSDC 73372) using cyanex as chelating agent

\begin{tabular}{cccccccc}
\hline $\begin{array}{c}\text { Set. } \\
\text { No }\end{array}$ & $\begin{array}{c}\text { Collection } \\
\text { solvent, } \\
10 \mathrm{~mL}\end{array}$ & $\begin{array}{c}\text { Modifier, } \\
0.5 \mathrm{~mL}\end{array}$ & $\begin{array}{c}\text { Ligand } \\
\text { volume, } \\
\mathrm{mL}\end{array}$ & $\begin{array}{c}\text { Pressure } \\
(\mathrm{psi})\end{array}$ & $\begin{array}{c}\text { Temperature } \\
{ }^{\circ} \mathrm{C}\end{array}$ & $\begin{array}{c}\text { Static } \\
\text { extraction } \\
\text { Time, min }\end{array}$ & $\begin{array}{c}\text { Dynamic } \\
\text { extraction } \\
\text { Time, min }\end{array}$ \\
\hline $\mathrm{I}$ & $3 \mathrm{M} \mathrm{HNO}_{3}$ & methanol & 0.25 & 2900 & 40 & 30 & 30 \\
II & chloroform & methanol & 0.25 & 2900 & 40 & 30 & 30 \\
III & $3 \mathrm{M} \mathrm{HNO}_{3}$ & none & 0.5 & 3480 & 60 & 30 & 40 \\
IV & $3 \mathrm{M} \mathrm{HNO}_{3}$ & water & 0.5 & 3480 & 60 & 30 & 40 \\
V & $3 \mathrm{M} \mathrm{HNO}_{3}$ & methanol & 0.5 & 3480 & 60 & 30 & 40 \\
VI & chloroform & $\mathrm{M} \mathrm{HNO}_{3}$ & 0.5 & 4400 & 60 & 20 & 30 \\
VII & chloroform & $1 \mathrm{M} \mathrm{HNO}_{3}$ & 0.5 & 3480 & 60 & 20 & 30 \\
\hline
\end{tabular}


The overall efficiencies (\% recoveries) of the SFE methods (using sets I to VII conditions in Table 1) were calculated from the amount of metal collected in the extracts, using the equation below. Note that these percent recoveries already include the efficiencies of the collection solvents also.

$$
\begin{aligned}
& \% \text { Recovery }=\frac{\text { Amount of metal collected, } \mu \mathrm{g}}{\text { Amount of metal in the CRM, } \mu \mathrm{g}^{*}} \times 100 \\
& \text { *based from certified value }
\end{aligned}
$$

\section{Validation of the optimized supercritical fluid extraction method}

From the seven sets of SFE conditions tested, the set that gave the highest recovery (the optimum set) was validated by comparing the recoveries of each metal to the recoveries obtained when the same CRMs were analyzed using two standard methods: AOAC Method 990.08 for $\mathrm{Cd}$ and $\mathrm{Pb}$ and EPA Method 200.7 for $\mathrm{Hg}, \mathrm{Cd}$ and $\mathrm{Pb}$, respectively. These two standard methods are both open vessel digestion procedures at $95{ }^{\circ} \mathrm{C}$. These validation techniques were also applied in the validation of a modified microwave-assisted digestion method published elsewhere ${ }^{11}$.

\section{Results and Discussion}

\section{Choice of collection solvent}

Optimization of the collection solvent was necessary since a range of suitable fluids were reported to be capable of obtaining quantitative metal complex recoveries, including methanol, chloroform, isobutyl methyl ketone or $10 \%$ nitric acid ${ }^{12}$ from different matrices. For example, several studies utilized chloroform to collect extracts from SFE of paper ${ }^{13}$ and filter. In this study, two solvents were evaluated: chloroform and nitric acid, as shown in Table 1 (Column 2). Results showed that chloroform is a better collection solvent compared to nitric acid as shown by the good percent recoveries of the target analytes (set II in Table 2: $103 \%$ for $\mathrm{Hg}, 91 \%$ for $\mathrm{Cd}$ and $89 \%$ for $\mathrm{Pb}$ ) with an overall recovery of $94 \%$. On the other hand, nitric acid gave only an overall recovery of $26 \%$ at same SFE conditions (set I). These results also highlight the utmost importance of evaluating the efficiency of a collection solvent for a supercritical fluid extraction method for metals.

Optimization of SFE conditions using bis(2,4,4-trimethylpentyl)monothiophosphinic acid or cyanex as chelating agent

Table 2 (columns 4, 5, 6) shows the mean percent recoveries of the SFE of CRM (NCSDC 73372) at different SFE conditions using cyanex described above as chelating agent. Note that the SFE conditions in set II $\left(\mathrm{P}=2900 \mathrm{psi}, \mathrm{T}=40{ }^{\circ} \mathrm{C}\right.$, static extraction time $=30 \mathrm{~min}$, dynamic extraction time $=30 \mathrm{~min}$ using chloroform as collection solvent and methanol as modifier) have shown to be the most efficient set of conditions for the SFE of $\mathrm{Hg}, \mathrm{Cd}$ and $\mathrm{Pb}$ from the sediment matrix. It is at these conditions that the percent recoveries of the target metal analytes were highest ( $103 \%$ for $\mathrm{Hg}, 91 \%$ for $\mathrm{Cd}, 89 \%$ for $\mathrm{Pb}$ ) and precise $(6.2 \% \mathrm{RSD}$ for $\mathrm{Hg}, 0.2 \% \mathrm{RSD}$ for $\mathrm{Cd}$ and $2.7 \% \mathrm{RSD}$ for $\mathrm{Pb}$ ), resulting in an overall percent recovery of $94 \%$ for the three metal analytes with very good overall \% RSD of $3.0 \%$. Thus, it is an accurate and precise method for extracting the selected heavy metals from lake sediments, based from its overall percent recovery and RSD values. On the other hand, the overall percent recoveries of the other sets of conditions (except Set II) range from 19\% to $88 \%$ only, with overall \% RSDs ranging from $5.4 \%$ to $44.1 \%$. 
Table 2. Optimization results at different SFE conditions showing the mean percent recoveries of $\mathrm{Hg}, \mathrm{Cd}$ and $\mathrm{Pb}$ from the SFE of CRM (NCSDC 73372) using cyanex as chelating agent

\begin{tabular}{|c|c|c|c|c|c|c|}
\hline $\begin{array}{l}\text { Set } \\
\text { No }\end{array}$ & $\begin{array}{l}\text { Collection } \\
\text { solvent, } \\
10 \mathrm{~mL} \\
\end{array}$ & $\begin{array}{l}\text { Modifier, } \\
0.5 \mathrm{~mL}\end{array}$ & $\begin{array}{c}\mathrm{Hg} \% \\
\text { Recovery } \\
{[\% \text { RSD] }}\end{array}$ & $\begin{array}{c}\mathrm{Cd} \% \\
\text { Recovery } \\
{[\% \text { RSD] }}\end{array}$ & $\begin{array}{c}\mathrm{Pb} \% \\
\text { Recovery } \\
{[\% \text { RSD] }}\end{array}$ & $\begin{array}{c}\text { Overall \% } \\
\text { Recovery }^{*}[\text { Overall } \\
\% \text { RSD }]^{* *}\end{array}$ \\
\hline I & $3 \mathrm{M} \mathrm{HNO}_{3}$ & methanol & $56[34.8]$ & $15[12.6]$ & $5.5[14.8]$ & $26[20.7]$ \\
\hline II & chloroform & methanol & $103[6.2]$ & $91[0.2]$ & $89[2.7]$ & $94[3.0]$ \\
\hline III & $3 \mathrm{M} \mathrm{HNO}_{3}$ & none & $98[8.4]$ & $23[0.5]$ & $17[17.2]$ & $46[8.7]$ \\
\hline IV & $3 \mathrm{M} \mathrm{HNO}_{3}$ & water & $28[52.3]$ & $16[21.3]$ & $12[58.6]$ & $19[44.1]$ \\
\hline $\mathrm{V}$ & $3 \mathrm{M} \mathrm{HNO}_{3}$ & methanol & $43[18.5]$ & $26[17.7]$ & $14[14.3]$ & $28[16.8]$ \\
\hline VI & Chloroform & $1 \mathrm{M} \mathrm{HNO}_{3}$ & $95[11.3]$ & $82[1.9]$ & $87[2.9]$ & $88[5.4]$ \\
\hline VII & Chloroform & $1 \mathrm{M} \mathrm{HNO}_{3}$ & nd & $2.1[14.1]$ & nd & $1.2^{\mathrm{na}}$ \\
\hline
\end{tabular}

$n d$ - not detected; * Overall \% Recovery is the average of the 3 individual \% recoveries; ${ }^{* *}$ Overall \% $R S D$ is the average of the 3 individual \% RSDs; na- not applicable

\section{Validation against EPA method 200.7 and AOAC method 990.08}

The accuracy of the method was validated by comparing the percent recoveries from the analysis of the CRM obtained using the optimized supercritical fluid extraction method to those obtained using two standard methods - EPA method 200.7 and AOAC method 990.08 (Table 3).

The results shown in Table 3 indicate that the optimized supercritical fluid extraction method achieved significantly better recovery values ( $94 \%$ for $\mathrm{Hg}, 93 \%$ for $\mathrm{Cd}$ and $89 \%$ for $\mathrm{Pb}$ ) for all target analytes from the lake sediment CRM (NCSDC 73372) compared to the two standard methods (EPA Method 200.7: 89\% for $\mathrm{Hg}$, 90\% for $\mathrm{Cd}, 86 \%$ for $\mathrm{Pb}$ and $\mathrm{AOAC}$ method 990.08: $85 \%$ for $\mathrm{Cd}, 87 \%$ for $\mathrm{Pb}$; note that this method is not applicable to $\mathrm{Hg}$ ). For example, the $\mathrm{Cd}$ in the CRM was only $90 \%$ and $85 \%$ recovered using EPA method 200.7 and AOAC method 990.08, respectively, compared to 93\% using the method being validated. Furthermore, the new method showed very good precision and repeatability with $\%$ RSD values ranging from 1.5 to $4.8 \%$.

In general, the percent recovery and precision values obtained in this study (Table 3) clearly show that the optimized supercritical fluid extraction method for metals using cyanex as chelating has been validated to be more accurate and precise than the two standard digestion methods (EPA method 200.7 and AOAC method 990.08) considered in the study. Thus, it can be used in the $\mathrm{SFE}$ of $\mathrm{Hg}, \mathrm{Cd}$ and $\mathrm{Pb}$ from sediment matrix for subsequent ICP-MS analysis.

Table 3. Validation results showing the percent recoveries (accuracy) and percent RSDs (precision) of the SFE of $\mathrm{Hg}, \mathrm{Cd}$ and $\mathrm{Pb}$ from lake sediment CRM as obtained using the optimized supercritical fluid extraction methods for metals compared with standard methods.

\begin{tabular}{|c|c|c|c|c|c|c|c|c|}
\hline \multirow{3}{*}{ Analyte } & \multirow{3}{*}{$\begin{array}{l}\text { Certified } \\
\text { values, } \\
\mathrm{mg} / \mathrm{kg}\end{array}$} & \multirow{3}{*}{$\begin{array}{l}\text { Recovered } \\
\text { values using } \\
\text { SFE, mg/kg }\end{array}$} & \multicolumn{2}{|c|}{$\begin{array}{c}\text { Supercritical fluid } \\
\text { extraction (Optimized) }\end{array}$} & \multicolumn{2}{|c|}{$\begin{array}{l}\text { EPA method } \\
200.7\end{array}$} & \multicolumn{2}{|c|}{$\begin{array}{c}\text { AOAC method } \\
990.08\end{array}$} \\
\hline & & & $\%$ & $\%$ & $\%$ & $\%$ & $\%$ & $\%$ \\
\hline & & & Recovery & RSD & Recovery & RSD & Recovery & RSD \\
\hline $\mathrm{Hg}$ & 0.030 & 0.028 & 94 & 1.8 & 89 & 2.5 & na & na \\
\hline $\mathrm{Cd}$ & 0.10 & 0.093 & 93 & 4.8 & 90 & 6.7 & 85 & 4.1 \\
\hline $\mathrm{Pb}$ & 25 & 22.2 & 89 & 1.5 & 86 & 2.4 & 87 & 1.5 \\
\hline
\end{tabular}




\section{Conclusion}

The optimized and validated supercritical fluid extraction method for metals using bis(2,4,4-trimethylpentyl)monothiophosphinic acid as chelating agent reported here is found to be rapid, precise and accurate. It also uses an environmentally friendly solvent (supercritical $\mathrm{CO}_{2}$ ). The percent recovery and RSD values clearly indicate the very good accuracy and reproducibility of the method. Thus, this SFE method could be recommended to be used in the extraction of $\mathrm{Hg}, \mathrm{Cd}$ and $\mathrm{Pb}$ from real sediment samples for subsequent ICP-MS analysis.

\section{Acknowledgment}

The researchers would like to acknowledge the Philippine Commission on Higher Education (CHED)-Higher Education Development Project-Faculty Development Program for financial support, the Mindanao State University at Naawan, together with the local government unit of Naawan (in Misamis Oriental, Philippines), for the assistance during the collection of samples for the method application phase and Queensland University of Technology (in Brisbane, Queensland, Australia) particularly the School of Physical and Chemical Sciences, for technical assistance in the use of the laboratories and instruments needed in the conduct of the study.

\section{References}

1. Baird C, Environmental Chemistry; Freeman W H \& Co: New York, 1995.

2. Burford M D, Ozel M Z, Clifford A A and Bartle K D, Analyst, 1999, 124, 609-614

3. Lui Y, Lopez-Avila V, Alcarez M and Beckert W F, J High Res Chromatogr, 1993, 16, 106.

4. Wang J and Marshall W D, Analyst, . 1995, 120, 623.

5. Lin Y H, Braver R D, Laintz K E and Wai C M, Anal Chem., 1993, 65, 2549.

6. Sun Y C, Chung Y T and Mierzwa J, Analyst, 2001, 126, 1694-1699.

7. Kersch C, van der Kraan M, Woerlee G F and Witkamp G J, J Chem Tech Biotechnol., 2002, 77(3), 256- 259.

8. Johansson M, Malmbeck R, Wierczinski Band Skarnemark G, J Radioanalytical Nuclear Chem., 2001, 250(3), 437-443.

9. Bjorklund E, Bowadt S, Nilsson T and Mathiassonet L, J Chromatogr A, 1999, 836, 285-293.

10. Smart N G, Carleson T E, Elshani S, Wang S, W ai C M, Ind Eng Chem Res., 1997, 36, 1819-1826.

11. Roa E C, Capangpangan M B and Schultz M, J Environ Chem Ecotoxicology In press, 2010.

12. Burford M D, Ozel M Z, Clifford A A and Bartle K D, Analyst, 1999, 124, 609-614.

13. Kumar P, Pal A and Saxena M K, Desalination, 2008, 232(1-3), 71-79. 


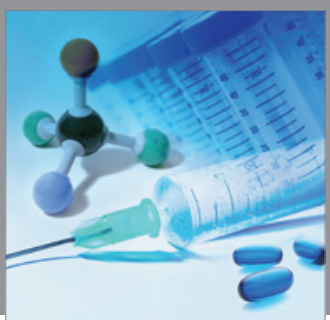

International Journal of

Medicinal Chemistry

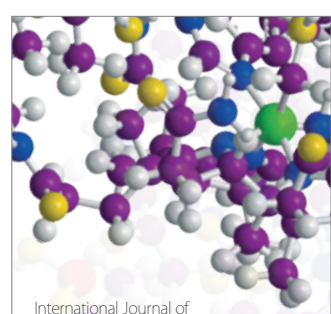

Carbohydrate Chemistry

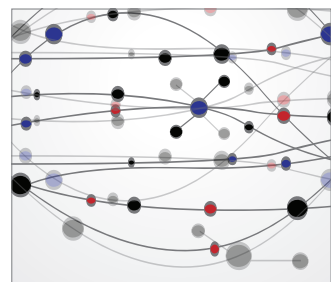

The Scientific World Journal
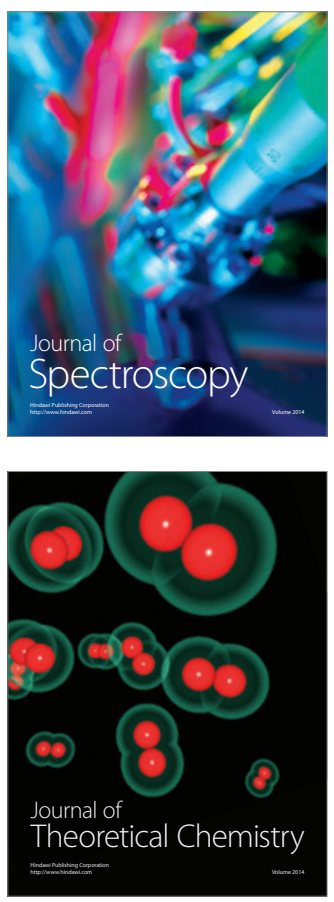
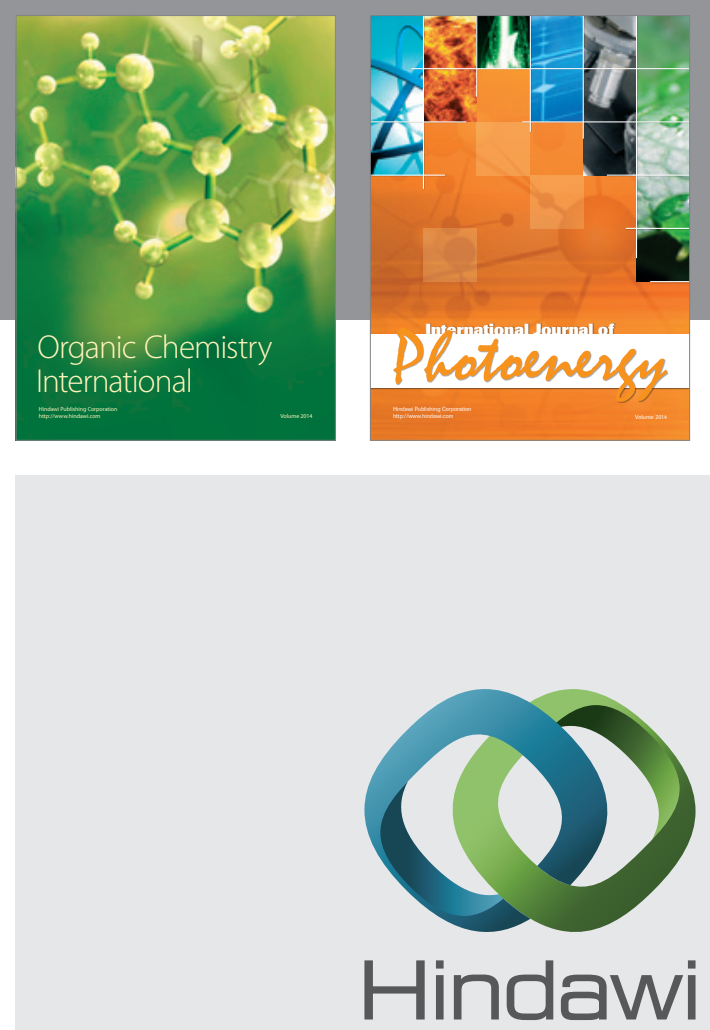

Submit your manuscripts at

http://www.hindawi.com
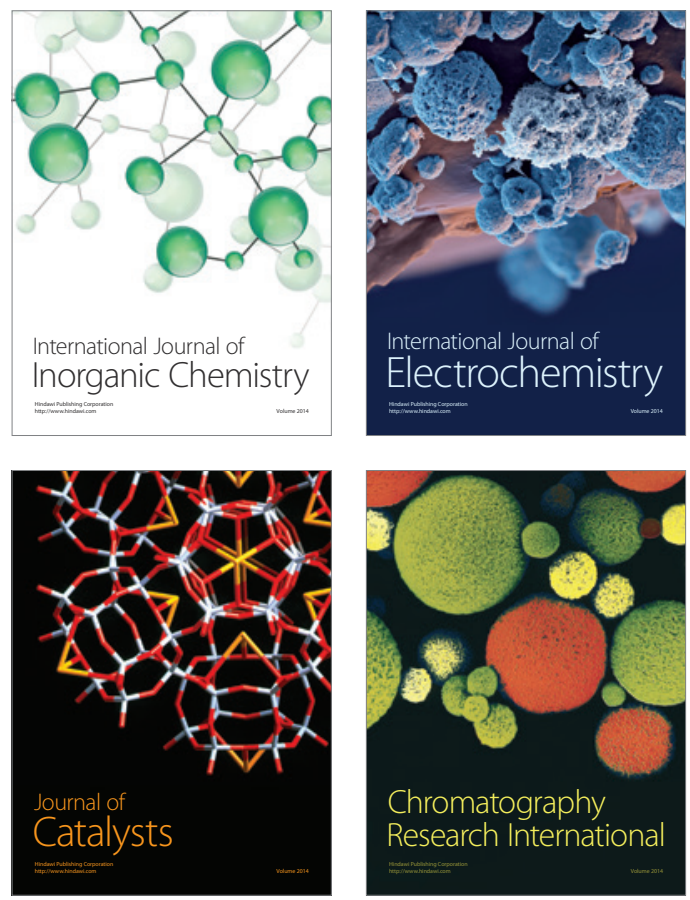
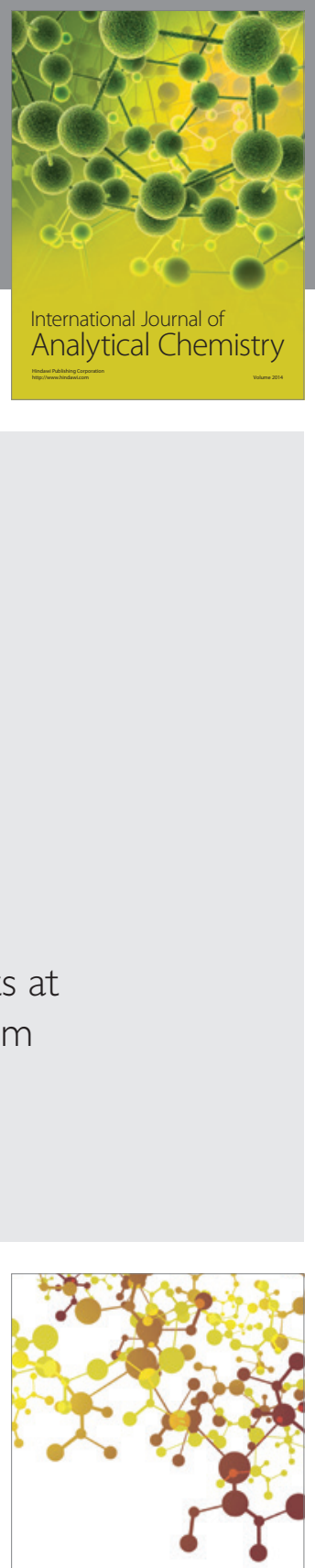

Journal of

Applied Chemistry
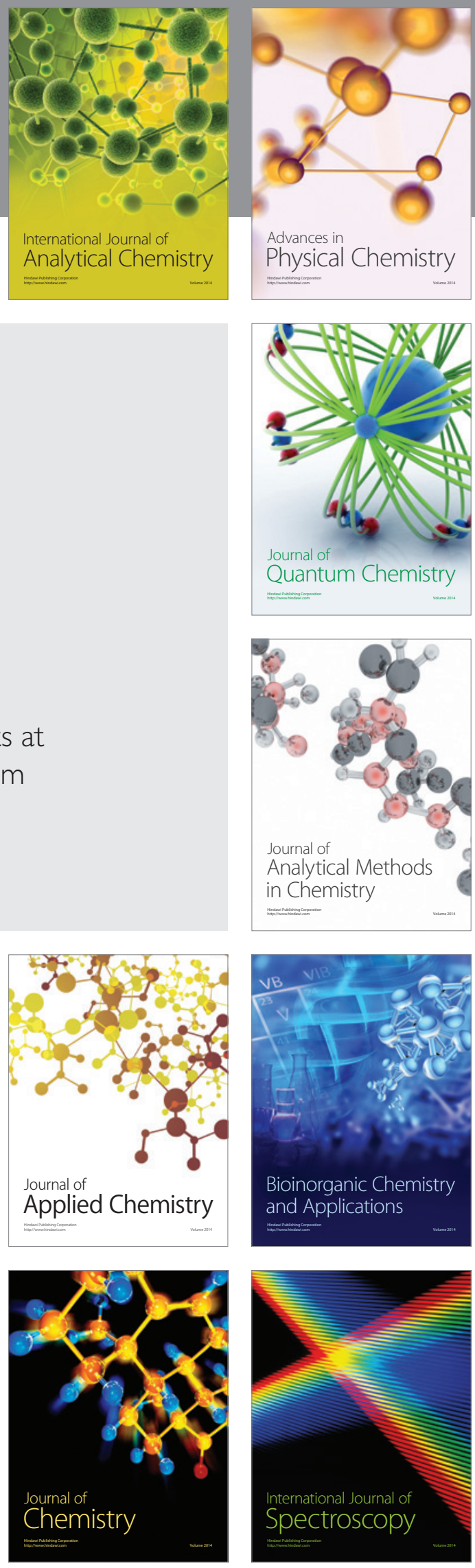